Brit. Heart f., 1967, 29, 548.

\title{
Myocardial Infarction and the Intrinsic Calibre of Coronary Arteries
}

\author{
GEOFFREY ROSE, RONALD J. PRINEAS, AND J. R. A. MITCHELL
}

From the Department of Medical Statistics and Epidemiology, The London School of Hygiene and Tropical Medicine, Keppel St., London W.C.1, and the Department of the Regius Professor of Medicine, Radcliffe Infirmary, Oxford

Thrombotic occlusion of a coronary artery occurs in most cases of fatal myocardial infarction (Mitchell and Schwartz, 1963; Allison et al., 1963), and it has been suggested that thrombosis is most likely to occur where the lumen is small (Osborn, 1963). Although the size of arterial plaques and the relative narrowing that they produce have been extensively studied, the absolute size of the effective lumen must also depend on the intrinsic calibre of the artery in which the lesions occur. This variable has occasionally been considered in work on animals (Tepperman and Pearlman, 1961; Stevenson et al., 1964), but in human disease it seems to have been ignored.

We have therefore measured intrinsic coronary artery calibre at necropsy in a representative sample of persons without infarction, and have compared the findings with those in a series of patients with necropsy evidence of infarction.

\section{Material aNd Methods}

Measurements were made on radiographs of injected coronary arteries obtained from two necropsy series at the Radcliffe Infirmary, Oxford (Schwartz and Mitchell, 1962; Mitchell and Schwartz, 1963). The first series, of 137 patients, was a consecutive 1 in 5 sample of necropsies on patients aged 35 years and over. In 15 cases there was pathological evidence of myocardial infarction, leaving 122 for the present study. The necropsy rate for hospital deaths is high (over $80 \%$ ); the sample is, therefore, presumed to be representative of hospital deaths. The second series comprised 79 cases with post-mortem evidence of myocardial infarction (acute or healed). The possible effects of selective bias will be considered in the discussion.

All injections were made at constant pressure $(80 \mathrm{~mm}$. $\mathrm{Hg}$ ). Radiographs from the two series were mixed together and all measurements were then made by one observer (R.J.P.) who did not know the subject's age, sex, or diagnosis. The right main coronary artery was

Received July 11, 1966. chosen for measurement because it was more consistently filled, had sharply defined inner walls, and relative freedom from disease.

Four measurements were made of the artery's internal diameter using dividers. The measurements were spaced evenly between the origin of the artery and the right border of the heart. If there was any suggestion of stenosis or intimal irregularity at any of the selected points, then measurements were taken instead at the two nearest points of apparent normality and their values averaged.

In the control series good measurements were possible in 92 cases $(75 \%: 50$ men and 42 women). In the infarction series they were possible in $36(46 \%: 24$ men and 12 women). In the remaining 73, excluded from the main analysis, poor filling or extensive disease prevented reliable measurements. However, some measurements were possible in 36 of these, and the pattern of their results proved to be similar to that of the main series.

Independent duplicate measurements were made in a randomly chosen 10 per cent of radiographs. In none of these did the average of the four readings differ by more than $0.125 \mathrm{~mm}$. on the two occasions.

It was fundamental to our purpose that the radiographic measurements should estimate the true intrinsic calibre of the artery at points unaffected by plaques. The adequacy of radiographic identification of disease was therefore investigated by comparison with serial histological sections. Each method was applied independently to assess whether in a particular right coronary artery there was any degree of stenosis at any point. Comparison of the findings (Table I) indicates close agreement, and so it is presumed that plaques could be reliably identified radiographically, and that the steps taken to avoid measurements at such points were adequate.

Next an assessment was made of the adequacy of right coronary artery diameter as an index of the diameters of major coronary arteries as a whole. This was based on a sample of 10 consecutive radiographs in which good filling and relative freedom from plaques permitted adequate measurements in all the main arteries (the left 548 
the right circumflex, and the left circumflex). The sum of the maximum diameters of these 5 arteries was found to correlate very highly with the diameter of the right coronary artery $(r=0.95)$, so that the latter alone is a sufficient index of the intrinsic calibre of the major vessels as a whole.

Analysis of artery diameters revealed an association with physical activity of occupation. The relation between occupation and the extent of coronary atherosclerosis was, therefore, also studied. The methods have been described already (Schwartz and Mitchell, 1962).

\section{RESULTS}

Table II sets out the age-specific mean diameters of the different groups. Among male control subjects the diameters increase progressively with age, men over 70 years having values 16 per cent greater than those under 50 years. Among women the trend is similar (apart from the youngest agegroup, where the divergence may be due only to small numbers); their arteries also tend to be smaller than those of men.

Values for the male infarction group show the same age trend, but they are consistently smaller than for the corresponding control subjects. The situation among women with infarction is probably similar.

In order to permit pooling of results from subjects of different ages, standardization was undertaken: the regressions of artery diameters on age were calculated separately for men in the control and the infarction groups, and the pooled regression was then used to adjust each individual reading to age 60. The process was repeated for women. The remainder of the results will relate to these adjusted values.

The mean age-adjusted diameter for the male infarction group is $0.46 \mathrm{~mm}$. less than the control value. This reduction is equivalent to a greater cross-sectional area among control subjects of approximately 30 per cent, and is very significant
TABLE I

AGREEMENT BETWEEN HISTOLOGICAL AND RADIOGRAPHIC ASSESSMENT OF STENOSIS OF RIGHT CORONARY ARTERY

\begin{tabular}{ll|c|c|c}
\hline & & \multicolumn{2}{|c}{ Histological assessment } \\
\cline { 4 - 5 } & & Present & Absent & Total \\
\hline Radiographic assessment & Present & 66 & 6 & 72 \\
& Absent & 3 & 53 & 56 \\
& Total & 69 & 59 & 128 \\
\hline
\end{tabular}

$(0.02>p>0.01)$. The difference between the two female groups is in the same direction.

The male groups were then divided according to physical activity of occupation, using so far as possible the same classification as Morris and Crawford (1961). The mean diameters for the various classes are given in Table III, and the distributions of individual values are shown in Fig. 1. Among control

\section{TABLE III}

MEAN RIGHT CORONARY ARTERY DIAMETERS (ADJUSTED TO AGE 60) IN MEN, ACCORDING TO PHYSICAL ACTIVITY OF OCCUPATION

\begin{tabular}{l|l|c|c}
\hline Activity of occupation & Group & $\begin{array}{c}\text { No. of } \\
\text { men }\end{array}$ & $\begin{array}{c}\text { Mean diameter } \\
\text { (and S.E.) } \\
\text { (mm.) }\end{array}$ \\
\hline Light & Control & 27 & $3.90( \pm 0 \cdot 17)$ \\
& Infarction & 11 & $3 \cdot 82( \pm 0 \cdot 22)$ \\
Active & Control & 12 & $4 \cdot 30( \pm 0 \cdot 11)$ \\
& Infarction & 9 & $3 \cdot 22( \pm 0 \cdot 19)$ \\
Heavy & Control & 7 & $3.98( \pm 0 \cdot 19)$ \\
(Retired or unknown) & Infarction & 3 & $2 \cdot 95( \pm 0 \cdot 10)$ \\
& Control & 4 & $3.35( \pm 0 \cdot 25)$ \\
& Infarction & 1 & $4 \cdot 22( \pm-2)$ \\
\hline
\end{tabular}

subjects, arteries tend to be larger in active than in light workers $(0.1>p>0.05)$, but this tendency is not maintained for the small group of heavy workers. When comparisons between infarction and control subjects are made within occupation groups, it appears that virtually the whole of the difference

TABLE II

NUMBERS OF SUBJECTS, AND MEAN INTRINSIC DIAMETERS OF RIGHT CORONARY ARTERIES

\begin{tabular}{|c|c|c|c|c|c|c|c|c|c|c|c|c|}
\hline \multirow[b]{3}{*}{ Sex } & \multirow[b]{3}{*}{ Group } & \multicolumn{11}{|c|}{ Age (yr.) } \\
\hline & & \multicolumn{2}{|r|}{$<50$} & \multicolumn{2}{|r|}{$50-$} & \multicolumn{2}{|r|}{$60-$} & \multicolumn{2}{|c|}{70 and over } & \multicolumn{3}{|r|}{ Total } \\
\hline & & No. & $\begin{array}{c}\text { Diameter } \\
\text { (mm.) }\end{array}$ & No. & $\begin{array}{c}\text { Diameter } \\
\text { (mm.) }\end{array}$ & No. & $\begin{array}{c}\text { Diameter } \\
\text { (mm.) }\end{array}$ & No. & $\begin{array}{c}\text { Diameter } \\
(\mathrm{mm} .)\end{array}$ & No. & $\underset{(\mathrm{mm} .)^{\star}}{\text { Diamer }}$ & S.E. \\
\hline Men & $\left\{\begin{array}{l}\text { Control } \\
\text { Infarction }\end{array}\right.$ & $\begin{array}{l}7 \\
2\end{array}$ & $\begin{array}{l}3.62 \\
3.25\end{array}$ & $\begin{array}{r}12 \\
5\end{array}$ & $\begin{array}{l}3.77 \\
3.53\end{array}$ & $\begin{array}{l}16 \\
11\end{array}$ & $\begin{array}{l}4 \cdot 17 \\
3 \cdot 50\end{array}$ & $\begin{array}{r}15 \\
6\end{array}$ & $\begin{array}{l}4 \cdot 19 \\
3 \cdot 85\end{array}$ & $\begin{array}{l}50 \\
24\end{array}$ & $\begin{array}{l}3.96 \\
3.50\end{array}$ & $\left.\begin{array}{l}0.107 \\
0.142\end{array}\right\} 0.02>P>0.01$ \\
\hline Women & $\left\{\begin{array}{l}\text { Control } \\
\text { Infarction }\end{array}\right.$ & $\frac{4}{-}$ & 3.81 & $\begin{array}{l}9 \\
1\end{array}$ & $\begin{array}{c}3.49 \\
(3 \cdot 63)\end{array}$ & $\begin{array}{r}13 \\
6\end{array}$ & $\begin{array}{l}3 \cdot 70 \\
3 \cdot 46\end{array}$ & $\begin{array}{r}16 \\
5\end{array}$ & $\begin{array}{l}3.78 \\
3.30\end{array}$ & $\begin{array}{l}42 \\
12\end{array}$ & $\begin{array}{l}3 \cdot 69 \\
3 \cdot 38\end{array}$ & $\left.\begin{array}{l}0.089 \\
0.139\end{array}\right\} 0.2>P>0.1$ \\
\hline
\end{tabular}

* Adjusted to age 60 . 


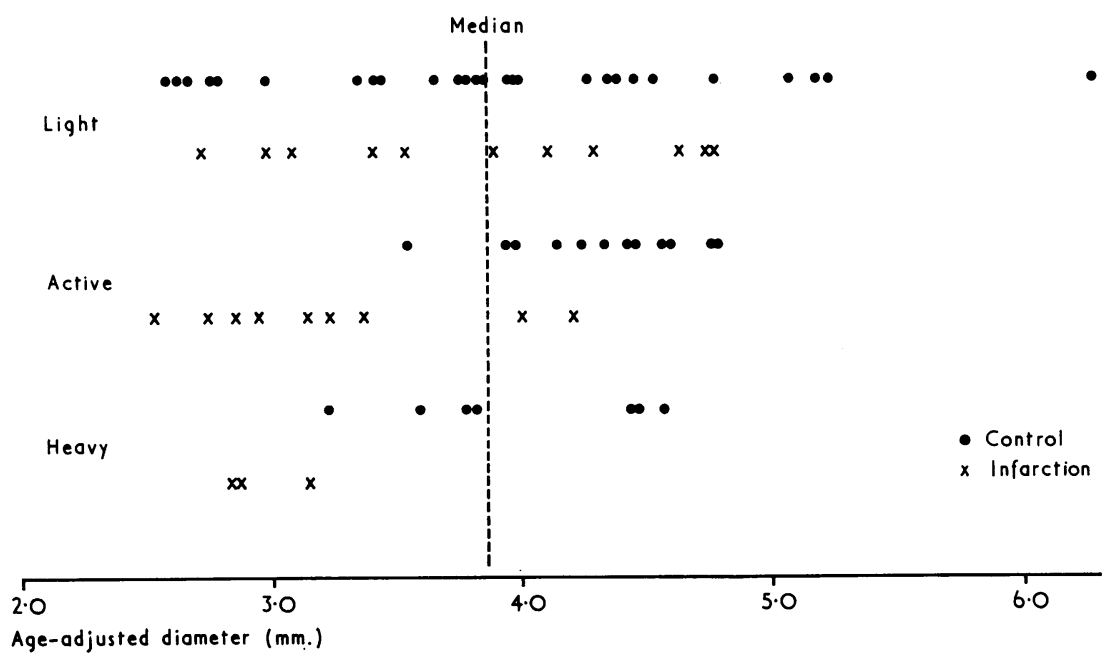

FIG. 1.-Distribution of right coronary artery diameters (adjusted to age 60) in men, according to physical activity of occupation.

previously noted is derived from the groups of active and heavy workers. Among light workers the mean difference is trivial; but among active workers the mean reduction in diameter in the infarction group is $1.08 \mathrm{~mm}$. ( $p<0.001)$, and among heavy workers it is about the same $(1.03 \mathrm{~mm}$.: $0.01>p>0.001)$. This is equivalent to a greater cross-sectional area among control subjects of approximately 75 per cent.

Coronary artery diameter was not significantly correlated with either heart weight or body height, nor was heart weight related to physical activity of occupation.

The numbers of control men in each occupation group may be considered as an indirect measure of the relative size of these three groups in the population from which the infarction cases were drawn; to the extent that this assumption is correct, the ratio of infarction to control cases provides an index of the incidence of infarction at necropsy among the respective occupational groups. In Fig. 1 a vertical line has been drawn at the median value for coronary artery diameter. To the left of this line, among light workers the ratio of infarction to control subjects is 0.4 to 1 ; but among active and heavy workers it is 2 to 1 . This difference is very significant. Conversely among men with larger arteries (to the right of the median line) the opposite is the case: the ratio among light workers is 0.5 infarction cases to 1 control, but among active and heavy workers it is 0.14 to 1 . There is thus some suggestion that among the "small artery" section of the population-by contrast with the "large artery" section-infarction may be commoner in active and heavy workers. There are, however, selective factors at work, which must make any such conclusion very tentative.

A full description has already been published (Schwartz and Mitchell, 1962; Mitchell and Schwartz, 1963) of the occurrence of atherosclerosis in the series as a whole, but not in relation to physical activity of occupation. This analysis, which bears on the present study, is illustrated in Fig. 2. The "control group" here consists of the 75 men in the original unselected series, excluding 8 subjects with large myocardial scars and 7 whose occupations were unknown. The "infarction group" consists of the 57 men in the original selected series, apart from 3 whose occupations were unknown. Because of small differences in age distributions, values have been age-adjusted.

Figure 2 shows that among control subjects occupation bears little or no relation to the mean coronary score (a composite index of atherosclerotic stenosis in the main coronary arteries). In the infarction group greater physical activity tends to be associated with lower scores, though the trend is not beyond chance limits.

\section{Discussion}

Ideally one would wish to study the coronary arteries of a representative sample of the general population; but at present this is impossible. The necropsy series from which the cases were derived is representative of all hospital deaths in the Oxford region, but the effect of excluding deaths at home cannot be estimated. The infarction group includes 


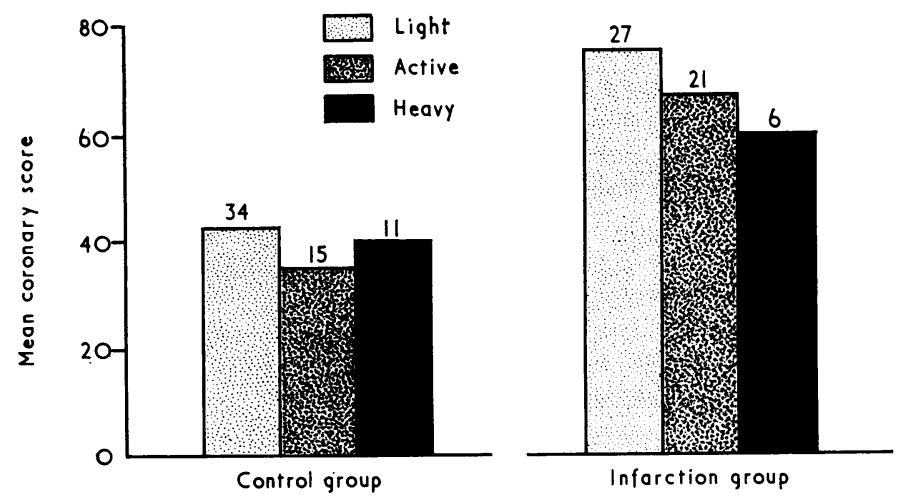

FIG. 2.-Average values (age-adjusted) for "mean coronary scores" in men, according to physical activity of occupation.

all persons with large myocardial scars. Most of them died as a direct result of their infarction, so that the results do not necessarily apply directly to non-fatal myocardial infarction in the living population. The case fatality ratio of acute myocardial infarction in the U.S.A. has been found to be twice as great among sedentary workers as among the physically active (Health Insurance Plan of Greater New York, 1964), and the same seems to be true in this country. This again limits generalization from occupational comparisons based on fatal cases.

Accurate measurements of intrinsic diameter were possible on only 75 per cent of the control series and 46 per cent of the infarction series. There was evidence that among the excluded cases the differences were in the same direction as those that are reported; but the excluded cases probably had worse than average arterial disease, so that our findings may underestimate the true difference between the two groups. Evidence has been given that measurements were precise and unbiased, and that the intrinsic diameter of the right coronary artery is an adequate index of the diameters of the other major coronary arteries.

The results indicate that the intrinsic diameter of the larger coronary arteries at necropsy, as measured in this study, is an important variable which is undoubtedly related to myocardial infarction and to its frequency in occupations of different levels of physical activity, and which strongly merits further investigation. This is our major conclusion: the interpretations of these inter-relations must at present be conjectural.

It appears that with increasing age the coronary arteries, like the aorta (Mitchell, Schwartz, and Zinger, 1964), tend to enlarge in both men and women. There was no clear effect of occupation on artery size, though the difference between light and active workers was almost significant. It has been found in rats that repeated physical exertion leads to an increase in size of the coronary artery tree (Tepperman and Pearlman, 1961; Stevenson et al., 1964).

We were able to measure the arterial size only after death, and so cannot comment on whether change of diameter within an individual over a period has any bearing on the occurrence of coronary thrombosis. The possibility must also be considered that the tendency to smaller arteries in the infarction group may have been a consequence of occlusion rather than a precursor. This, however, seems very unlikely, partly because the right coronary artery (which we measured) was not often occluded, and also because it is inconsistent with the finding within the infarction series that the group with most atherosclerotic stenosis (the light workers) had the largest arteries.

The most striking occupational effect is the 75 per cent greater cross-sectional area in control as opposed to infarction cases among the active and heavy workers. The almost complete absence of such a difference among light workers is surprising. It may be that physical activity partly protects an individual from the occurrence of infarction, and that this protection only breaks down when a man is unfortunate enough to have small coronary arteries. The results in Fig. 1 are consistent with such an interpretation for subjects with arterial diameters above the median value; but there is some suggestion that for persons with small arteries the risk of infarction may actually be greater among the active than the sedentary. However, complicated selection factors are involved, and caution must be exercised in using such material to answer an epidemiological question.

Measurements were made on vessels that had 
been injected at a pressure which was the same for all subjects. This implies that the in vivo arterial calibre of persons with higher blood pressures may have been underestimated. Thus, the in vivo increase of calibre with age may have been larger than is indicated, since old people tend to have higher blood pressures. The occupational differences are unlikely to have been much affected, since occupational differences in blood pressure are relatively small (Karvonen et al., 1961).

On the other hand, persons developing infarction - whom we found to have smaller estimated calibres -tend to have higher blood pressures than others of the same age. Hence their in vivo arterial calibres, and the degree to which they were smaller than in the control group, may have been underestimated. But among active and heavy workers we found cross-sectional areas 75 per cent greater in controls than in infarction cases. Clearly any difference in blood pressure could at most account for a small part of the observed difference.

Our findings agree with those of Morris and Crawford (1961) in failing to show within a group without infarction any clear relation between coronary atherosclerosis and physical activity of occupation. In general physical activity is associated with some protection against infarction (Morris et al., 1953; Taylor et al., 1962), but seemingly this is mediated by some pathway other than atherosclerosis. One might, therefore, have expected that the occurrence of infarction in heavy workers would require more severe atherosclerotic stenosis than in the case of light workers. This, however, seems not to be the case (Fig. 2): if anything, active workers with infarction have less coronary atherosclerosis, not more.

Further investigation of these problems is needed, based on larger numbers (especially of heavy workers), so as to permit more extensive age-specific comparisons and the study of age trends. The relation between activity and artery size in subjects without infarction-which remains uncertain on the present results-could also be clarified by a larger necropsy study. The evaluation of the relation between activity, risk of infarction, and death, and the state of the coronary arteries, requires a prospective epidemiological study linked with post-mortem examination.

\section{SUMMARY}

Measurements of intrinsic coronary artery calibre, at sites free from plaques, are reported for repre- sentative series of control and infarction cases, using radiographs of post-mortem coronary angiograms. As measured under these conditions, the calibre increased with age in both groups. At each individual age the arteries of the infarction group were smaller than those of control subjects.

Analysis in relation to physical activity of occupation in men showed that among active and heavy workers the cross-sectional area for infarction-free subjects was 75 per cent greater than in the corresponding infarction groups, this difference being highly significant. Among light workers there was little difference.

There was some suggestion that in control subjects active work tends to be associated with larger arteries.

We are grateful to Mrs. E. Killick for assistance in the analysis.

\section{REFERENCES}

Allison, R. B., Rodriguez, F. L., Higgins, E. A., Leddy, J. P., Abelmann, W. H., Ellis, L. B., and Robbins, S. L. (1963). Clinicopathologic correlations in coronary atherosclerosis. Circulation, 27, 170.

Health Insurance Plan of Greater New York (1964). Division of Research and Statistics, New York, N.Y.

Karvonen, M. J., Rautaharju, P. M., Orma, E., Punsar, S., and Takkunen, J. (1961). Heart disease and employment. Cardiovascular studies on lumberjacks. $\mathfrak{f}$. occup. Med., 3, 49.

Mitchell, J. R. A., and Schwartz, C. J. (1963). The relation between myocardial lesions and coronary artery disease. II. A selected group of patients with massive cardiac necrosis or scarring. Brit. Heart f., 25, 1.

$\longrightarrow,-$, and Zinger, A. (1964). Relationship between aortic plaques and age, sex, and blood pressure. Brit. med. F., 1, 205.

Morris, J. N., and Crawford, M. D. (1961). Atherosclerosis and coronary (ischæmic) heart-disease. Lancet, 1, 47.

, Heady, J. A., Raffie, P. A. B., Roberts, C. G., and Parks, J. W. (1953). Coronary heart-disease and physical activity of work. Lancet, 2, 1053 and 1111.

Osborn, G. R. (1963). The Incubation Period of Coronary Thrombosis. Butterworths, London.

Schwartz, C. J., and Mitchell, J. R. A. (1962). The relation between myocardial lesions and coronary artery disease. I. An unselected necropsy study. Brit. Heart $\mathcal{F}$., 24, 761.

Stevenson, J. A. F., Feleki, V., Rechnitzer, P., and Beaton, J. R. (1964). Effect of exercise on coronary tree size in the rat. Circulat. Res., 15, 265.

Taylor, H. L., Klepetar, E., Keys, A., Parlin, W., Blackburn, H., and Puchner, T. (1962). Death rates among physically active and sedentary employees of the railroad industry. Amer. F. publ. Hlth, 52, 1697.

Tepperman, J., and Pearlman, D. (1961). Effects of exercise and anemia on coronary arteries of small animals as revealed by the corrosion-cast technique. Circulat. Res., 9, 576. 